\title{
Os partos e as maternidades em Portugal (1889-1943) - os casos nas cidades de Lisboa, Porto e Coimbra
}

\section{Deliveries and maternity wards in Portugal (1889-1943) - the cases of Lisbon, Porto and Coimbra}

\author{
Virgínia Baptista*
}

\begin{abstract}
Resumo
O objetivo deste artigo é debater os partos, e seus contextos familiares e sociais, realizados por médicos, a nível regional, em três cidades de Portugal - Lisboa, Porto e Coimbra- entre 1899 e 1943. As datas referem-se aos anos em que começámos e finalizámos as pesquisas nos livros de inscrição das parturientes, em duas maternidades de Lisboa. Pretendemos responder a três questões principais: - Qual a visão política e social da época sobre o trabalho das mulheres? Houve evolução nos cuidados de saúde das parturientes e dos recém-nascidos? Que sistemas de proteção social foram concedidos às mulheres quando chegavam às maternidades? Seguindo diferentes fontes, concluímos que só as mulheres trabalhadoras mais pobres obtinham assistência social para os partos nos hospitais enquanto só algumas mulheres acediam à previdência social pelo mutualismo ou pelos empregadores.
\end{abstract}

Palavras-chave: Mulheres trabalhadoras; maternidades; nascimentos

\begin{abstract}
The aim of this paper is to discuss deliveries and their social and family contexts in maternity hospitals provided by doctors at a regional level, in three cities of Portugal - Lisbon, Oporto and Coimbra- between 1899 and 1943. We started and finalized the research in the mother's registration books in two maternity hospitals in Lisbon by the dates specified. The given dates refer to the beginning and end of our research in the mother's registration books of two Lisbon maternity hospitals. We aim to answer to three main questions: What was the sociopolitical vision existing at the time about women's work? There were improvements in health care for mothers and newborns? What were the social protections that women achieved when they accessed to maternity hospitals? Following different sources, we conclude that only the poorest working women resorted to public assistance for deliveries in hospitals while few women acceded to social security through mutualism or their employers.
\end{abstract}

Keywords: Working women; maternity hospitals; births

\footnotetext{
*Doutora em História. Professora do Instituto de História Contemporânea / Universidade Nova de Lisboa. E-mail: virbaptista@gmail.com
} 


\section{Introdução}

Este artigo aborda os partos das mulheres, em maternidades portuguesas, destacando-se os casos regionais das cidades de Lisboa, Porto e Coimbra, entre 1889 e 1943. Baseámo-nos em fontes primárias que articulámos, sempre que possível, com bibliografia médica, de feministas, mutualistas e legislação das épocas. Será importante relevar que há dados omissos nas fontes, o que não inviabiliza as principais conclusões deste estudo.

As balizas cronológicas explicam-se por na enfermaria de partos de Santa Bárbara, também denominada por maternidade de Santa Bárbara, o primeiro livro de registos de nascimentos preservado ser de 1889 e 1943 foi o ano limite para a pesquisa nos livros de registos de nascimentos, na maternidade Dr. Alfredo da Costa, por motivos legais. As maternidades que analisamos foram estudadas pelo acesso permitido a fontes primárias, manuscritas ou impressas, relativamente às parturientes admitidas. Estas fontes proporcionam, também, uma perspetiva global sobre os partos em diversos meios hospitalares públicos e privados.

Em primeiro lugar, pretendemos mostrar a visão social e política das épocas que ligava o trabalho das mulheres à mortalidade infantil. Em consequência desta preocupação procuramos identificar a conceção prevalecente relativamente ao local onde deveriam ocorrer os partos, os nascimentos, ao longo de meio século. Outro propósito é o de observar os dados sociofamiliares das parturientes nas maternidades. Visamos perceber: quem eram as parturientes que recorriam às maternidades para nelas terem os partos? Quais as suas profissões e as dos progenitores das crianças? Por fim, propomo-nos verificar, nesta área da saúde materno-infantil, que refletiu as políticas relativamente às grávidas e à natalidade, quais os sistemas de proteção social estatais e privados disponibilizados às mulheres trabalhadoras.

Este estudo decorre ao longo de quatro regimes políticos, em Portugal: final da monarquia, I República, ditadura militar e Estado Novo, pelo que procuramos identificar as continuidades e as ruturas sobre os partos e os cuidados médicos nas maternidades. ${ }^{1}$

\section{As mulheres trabalhadoras e a mortalidade infantil}

Em Portugal, as mulheres estavam integradas no mercado de trabalho principalmente nas cidades de Lisboa e do Porto. Segundo os Recenseamentos

\footnotetext{
${ }^{1}$ A Monarquia decorreu até 1910, a I República entre 5 de Outubro de 1910 e 28 de Maio de 1926, a Ditadura Militar, de 28 de Maio de 1926 até 1933 (ano da publicação da Constituição) e o Estado Novo, desde 1933 até 25 de Abril de 1974 (o início do regime democrático).
} 
Gerais da População, apesar de oscilações decenais (devido à mudança das taxionomias de classificação das profissões e à evolução do conceito de população ativa), a nível nacional, as mulheres, em 1890, eram 36,4\% da população ativa e, em 1940, 22,8\% (não sendo contabilizadas muitas trabalhadoras na agricultura e em trabalhos no domicílio). ${ }^{2}$ Em Lisboa, as trabalhadoras rondaram os $29 \%$ dos ativos e, no Porto, a percentagem era superior, cerca de $37 \%$, durante todo o período. Ainda segundo estas fontes, em todos os setores profissionais, a maioria das mulheres tinha entre 20 e 40 anos, logo as trabalhadoras estavam em idade de fecundidade e constituíam famílias.

A questão do trabalho das mulheres e suas consequências para a maternidade, a família e para a sociedade não passou despercebida ao poder político, aos meios médicos e associativos que recearam por graves problemas demográficos, como a queda da natalidade e o aumento da mortalidade infantil.

Desde finais do século XIX que médicos e higienistas debatiam em congressos nacionais e internacionais, em revistas da especialidade e apresentavam dissertações às Escolas Médico-Cirúrgicas de Lisboa e do Porto (1836-1911) e à Faculdade de Medicina da Universidade de Coimbra ${ }^{3}$ sobre a falta de proteção à mulher grávida pobre e a grande mortalidade infantil, principalmente nas cidades de Lisboa e do Porto. Todos estes profissionais defendiam a necessidade da organização da assistência materno-infantil através de diversas instituições, como as maternidades.

Manuel Vicente Alfredo da Costa (1859-1910), professor da Escola Médico-Cirúrgica de Lisboa e médico obstetra no Hospital de S. José, em 14 de Novembro de 1899, iniciou o ano letivo, do curso de obstetrícia, com uma aula sobre a: "Protecção às mulheres grávidas pobres, como meio de promover o desenvolvimento fetal e de contribuir para suster até certo ponto a atrofia e o depauperamento físico de novas gerações". Urgia a legislação e a prática do descanso das mulheres trabalhadoras no final da gravidez, demonstrando-se a sua importância para o desenvolvimento do feto e o nascimento saudável dos filhos. Ao contrário, o trabalho excessivo podia ter consequências dramáticas para a vida adulta: "O prematuro como o débil de nascença é em

\footnotetext{
${ }^{2}$ Os Recenseamentos Gerais da População realizaram-se em 1890, 1900, 1930 e 1940. Há ainda um recenseamento extraordinário para as cidades de Lisboa e do Porto em 1925. Recenseamentos Gerais da População, 1890- 1940.

${ }^{3}$ A Universidade de Coimbra, a mais antiga de Portugal, foi fundada em 1290, sendo logo criada a Faculdade de Medicina.
} 
geral o condenado a uma vida inteira de fraqueza corporal em que amiúde se enxertam as distrofias, as nevropatias e as moléstias consumptivas". ${ }^{4}$

No ano seguinte, a médica e feminista Adelaide Cabette (1867-1935) apresentou à Escola Médico-Cirúrgica de Lisboa, a 26 de Julho, uma dissertação intitulada A proteção às Mulheres grávidas pobres como meio de promover o desenvolvimento físico de novas gerações. Propunha, entre outras medidas, para proteção das mulheres grávidas: a promulgação de uma lei estabelecendo o descanso de um mês antes do parto, com um subsídio, para as mulheres a trabalhar em fábricas e em estabelecimentos do Estado ou de particulares, a criação de maternidades, nomeadamente na capital, a implementação de mutualidades maternas, com o fim de apoiarem as mulheres pobres durante a gravidez e prestarem-lhe os devidos cuidados no domicílio. ${ }^{5}$

A mortalidade infantil era considerada o grande flagelo nacional, superior nos grandes aglomerados urbanos, de Lisboa e do Porto. Era visto como um reflexo das precárias condições de vida das populações, principalmente dos baixos salários masculinos, que levava as mulheres casadas a trabalhar. Não existindo dados muito precisos para anos recuados, foi possível avaliar que em 1890, na cidade do Porto, a mortalidade infantil era de $243 \%$. A nível nacional, em 1920, a taxa era de $173,1 \%$, sendo em Lisboa de $188,6 \%$, e, no Porto, de $223,3 \%$. Em 1940, tinha decrescido em Lisboa para $186,8 \%$ e no Porto para $191,1 \%{ }^{6}{ }^{6}$

Entre as doenças que maior mortalidade provocavam nos bebés estavam as doenças gastrointestinais atribuídas à ausência ou deficiente aleitamento materno, à reduzida higiene alimentar, as doenças bronco-pulmonares, devidas à insalubridade das habitações mais humildes e as debilidades congénitas, sendo as crianças ilegítimas as mais vulneráveis. ${ }^{7}$

Um ano após a implantação da República, em 1911, o médico Sebastião Cabral da Costa Sacadura (1872-1966), nos seus artigos e palestras, insistia que era vital para o país a criação de instituições de proteção às mulheres grávidas,

\footnotetext{
${ }^{4}$ COSTA, Alfredo da. "A protecção às mulheres grávidas pobres: Curso de Obstetrícia da Escola MédicoCirúrgica de Lisboa, ano lectivo de 1899-1900. Lição de abertura, 14 de Novembro de 1899” In Revista Portuguesa de Medicina e Cirurgia Práticas. Lisboa. Tipografia do Dia, 30 Dezembro de 1899, n.․ 76, p. 101.

${ }^{5}$ Decreto de 14 de Abril de 1891, "Regularizando o trabalho das mulheres e dos menores em fábricas e oficinas", Diário do Governo n.․ 88, I série, 22 de Abril de 1891, p. 882.

${ }^{6}$ MIRANDA, Sacuntala de, “A população portuguesa no século XX: Ensaio de demografia histórica” In Ler História. Lisboa, Ed. Teorema, 1990, n.ำ 18, 1990, pp. 68-69.

${ }^{7}$ RAMOS, Raymundo António. A Assistência à Mulher Grávida e ao Recém-Nascido. Porto, Ed. Imprensa Social, 1910, pp. 20-21. O autor indicou as seguintes taxas: 33,5\% para as doenças do aparelho digestivo, $21,3 \%$ para as debilidades congénitas e 16,5\% para as doenças do aparelho respiratório.
} 
como maternidades, principalmente para as mulheres que eram obrigadas a trabalhar até ao parto, por necessidades económicas, para as grávidas abandonadas e para os recém-nascidos, combatendo-se a mortalidade infantil. Defendeu a criação de instituições destinadas à higiene social - a puericultura, a exemplo do que acontecia em países como a Bélgica ou a Suíça. ${ }^{8}$

Também nos meios associativos do mutualismo, da entreajuda entre pessoas que residiam na mesma região, ou de trabalhadores em profissões similares, a proteção às mulheres trabalhadoras grávidas e a criação de instituições como as maternidades foram assuntos tratados nas assembleias mutualistas.

No Congresso Mutualista de 1911, em Lisboa, o médico e dirigente mutualista Estevão de Vasconcelos (1868-1917) na tese que apresentou "Do papel da mutualidade nos acidentes de trabalho - da acção do Estado no trabalho do operariado em geral - leis de protecção aos menores e às mulheres, e especialmente no período da gravidez", defendeu que as mulheres durantes as quatro semanas em que estavam impossibilitadas de trabalhar fossem remuneradas e a criação de maternidades e de asilos para as mulheres que não se pudessem tratar, devidamente, em suas casas. ${ }^{9}$ O médico e subdelegado de Saúde, Samuel Maia, (1874-1951) apresentou uma palestra intitulada "Da acção da mutualidade materna e infantil. Criação de Maternidades e de Dispensários de Assistência Infantil - as Gotas de Leite". Além de demonstrar a premência da proteção às mães trabalhadoras durante e após a gravidez, reiterou a urgência da criação de instituições fornecedoras de cuidados materno-infantis, maternidades e mutualidades maternas.

Já em ditadura miliar, em 1927, decretou-se sobre o funcionamento de maternidades fabris e de outros estabelecimentos em que se concentrassem muitas mulheres: "os grandes estabelecimentos em que trabalhem mais de 400 mulheres terão uma maternidade com as necessárias acomodações e condições" ${ }^{10}$ No preâmbulo do decreto invoca-se a necessidade de coadunar a legislação portuguesa com a internacional, nomeadamente com a Convenção de Washington, de 1919, sobre a proteção das mulheres trabalhadoras e das menores. Observava o legislador que nos meios fabris a fecundidade era menor

\footnotetext{
${ }^{8}$ SACADURA, S. C. da Costa. Protecção à Primeira Infância: na Sessão Solene da Associação Protectora da Primeira Infância em 25/12/1911. Lisboa. Ed. Tipografia Cristóvão Augusto Rodrigues Lda, 1919, pp. 7-16.

${ }^{9}$ Primeiro Congresso Nacional de Mutualidade Realizado em Lisboa nos dias 18 a 22 de Junho de 1911, na Sala Portugal da Sociedade de Geografia e no Salão Nobre do Theatro Nacional Almeida Garrett. Relatório: Theses, Actas das Sessões e Documentos, publicados sob a direcção do Secretário Geral do Congresso José Ernesto Dias da Silva, Lisboa, Companhia Nacional, 1911, pp. 56-59.

${ }^{10}$ Decreto n. 14 498, Diário do Governo n.․2 240, I série, 29 de Outubro de 1927, Sábado, art. 18. pp. 2134-2136.
} 
devido ao emprego das mulheres casadas, o que levava à diminuição da natalidade e ao aumento da mortalidade infantil, de nados-mortos, de abortos e de partos prematuros.

\section{Partos em casa ou nas maternidades?}

Em toda a época discutiu-se sobre o local próprio onde deveriam ocorrer os partos. Até à década de 40 , do século XX, a maioria dos nascimentos ocorria em casa, acompanhados, por vezes, pela parteira, pela curiosa, ou por mulheres mais experientes na "arte de dar à luz". Esta prática era o reflexo da ideologia política e social dominante.

No Congresso Mutualista de 1911, o já mencionado médico Samuel Maia defendeu a existência de visitadoras domiciliárias que aconselhassem as parturientes, por considerar que o parto deveria ocorrer no lar: "A mãe permanece em sua casa, não se desloca, abandonando os filhos que vão para a rua vadiar, nem o marido que poderá sentir-se atraído pelo vício para lugares onde a moral não floresce". ${ }^{11}$

Nos anos 30 do século XX, Costa Sacadura proferiu a sua opinião sobre este assunto:

“... as minhas preferências pelos partos normais sempre nos domicílios - seu ambiente tradicional - mas sempre e também sob um regime de assistência bem organizada, e na condição essencial da existência, para muitas mulheres, de domicílio". ${ }^{12}$

Logo, o nascimento deveria ocorrer no lar, o "santuário familiar" adequado, evitando-se os desvios familiares dos maridos e o abandono dos filhos. Para as maternidades ficavam os casos das mulheres das classes mais humildes - sem domicílio, abandonadas, ou as mulheres cujos partos que se previam complicados.

Por seu lado, Augusto de Almeida Monjardino (1871-1941), diretor da Maternidade Dr. Alfredo da Costa, pronunciou-se, com precaução, sobre a questão do parto domiciliário, em sessão de abertura do ano académico de 1938-1939, demonstrando os malefícios e inconvenientes sobre a propaganda dos partos no domicílio, principalmente para as mulheres das classes trabalhadoras desfavorecidas:

\footnotetext{
${ }^{11}$ Primeiro Congresso Nacional de Mutualidade...., Samuel Maia, p. 117.

${ }^{12}$ SACADURA, S. C. Costa. As Maternidades e a Familia. Conferência pronunciada em 26 de Maio de 1939 na Associação dos Médicos Católicos, separata da Acção Médica. Lisboa, Imprensa Lucas \& C. ${ }^{\text {, Julho }} 1939$, fasc. XIII, pp. 10-11.
} 
“É necessário estar em contacto com a situação de miséria em que essas mulheres se encontram, a braços com a fome, quando necessitam de uma alimentação reforçada; conhecer o conforto em que vivem; muitas vezes sem cama, sem agasalho, sem higiene alguma. Faça-se a propaganda do parto domiciliário; mas antes de mais nada dê-se-lhes um domicílio digno desse nome e dêem-se-lhes os recursos suficientes para poderem gerar um filho sadio e robusto". ${ }^{13}$

Era certo que no século XIX, com o desenvolvimento do estabelecimento de maternidades, em vários países europeus, verificou-se que a mortalidade das puérperas, que nelas tinham os partos, era superior relativamente às que tinham os partos em casa. Os motivos deviam-se a infeções puerperais por falta de cuidados antissépticos nas enfermarias e pela intervenção descuidada de alguns médicos nos partos, sem a adequada desinfeção das mãos. No final do século XIX emergia a obstetrícia e a valorização das maternidades. Em Portugal, o médico francês Adolph Pinard (1844-1934), o inventor da puericultura, foi a fonte para os médicos portugueses que o consideram o modelo a seguir. ${ }^{14}$

Se o lema nacional durante todo o período foi a defesa dos partos no domicílio, por motivos morais e afetivos, nascia-se, também, em hospitais, em antigas enfermarias e nas maternidades, que desde o início do século XX começaram a ser criadas.

Tendo em conta os problemas constatados, abordaremos os casos regionais de maternidades situadas em Lisboa, Porto e Coimbra, procurando identificar o seu funcionamento e os contextos familiares e sociais das mulheres e famílias que a elas recorriam.

\section{A enfermaria de partos de Santa Bárbara - a assistência pública às mães mais desprotegidas (1899-1920)}

O início da assistência à mulher grávida, em Lisboa, dá-se com a criação da enfermaria de Santa Bárbara, em 1755, no Hospital Real de S. José: “das nove enfermarias destinadas a mulheres, numeradas de 14 a 22, a n. 18, denominada de Santa Bárbara é destinada a paridas". ${ }^{15}$

\footnotetext{
${ }^{13}$ MONJARDINO, Augusto. Protecção à Maternidade e à Infância. Conferência realizada na Maternidade Dr. Alfredo da Costa, no dia 15 de Julho de 1938, separata de Arquivo de Obstetrícia e Ginecologia, Vol. III, ‥2, 1938 , p. 6.

${ }^{14}$ «Maternidade» In Grande Enciclopédia Portuguesa e Brasileira, Lisboa, Rio de Janeiro, Ed. Enciclopédia Lda., s/d, Vol. XVI, pp. 578-580.

${ }^{15}$ SACADURA, S. C. Costa, Subsídios para a História das Maternidades de Lisboa. Enfermaria de Partos de Santa Bárbara, Lisboa, s/ed, 1939, p. 11.
} 
Esta enfermaria de partos, também denominada por maternidade, de exíguas dimensões, funcionou durante meio século como maternidade provisória, apenas possuindo 55 camas, sendo a única maternidade pública em Lisboa, até 1932 (ano da inauguração da Maternidade Dr. Alfredo da Costa). Em 1905, as aulas de obstetrícia, frequentadas por 57 alunos, decorriam numa sala da Maternidade, desprovida de condições.

Desde finais do século XIX que o Professor Alfredo da Costa, regente da cadeira de obstetrícia na Escola Médico-Cirúrgica de Lisboa, pugnava pela construção de uma maternidade em Lisboa. Em 1906, dirigindo a Maternidade de Santa Bárbara denunciou as múltiplas deficiências do serviço ao Conselho da Escola Médico-Cirúrgica:

"Lisboa não tem a bem dizer uma Maternidade... o espaço, porém, exíguo mal
permite ali os mais rudimentares serviços de uma clínica regular. Puérperas,
de todos os matizes, vivem juntas, numa promiscuidade nefasta. Tuberculosas,
sifilíticas, erisipeladas, ulcerosas, eclâmpticas e maníacas, tudo se mistura ali
numa única sala, em contacto perigoso e anti-cirúrgico". ${ }^{16}$

No início do século XX, a maternidade assistia cerca de um milhar de mulheres por ano, por dia chegavam a ocorrer 8 a 10 partos. A mortalidade infantil era elevada, revelando as estatísticas fornecidas por Costa Sacadura, em 1911, a percentagem de 10,86\% de nados-mortos e de 18,55\% de bebés falecidos nos primeiros quinze dias, sendo a mortalidade global de $27,50 \%{ }^{17}$

Em 1937, Sebastião Cabral da Costa Sacadura era o diretor da clínica obstétrica de Santa Bárbara, altura em ocorreu uma beneficiação da maternidade, com a melhoria das condições em todos os serviços e a criação de novas salas.

Consultámos os livros de registos de nascimentos nos anos de 1899 (o primeiro preservado, como já referimos), 1910 e 1920 (não existe livro de registos de Janeiro a Março). ${ }^{18}$ Identificámos os seguintes números de parturientes: em 1899, 906, em 1910, 1004 e em 1920, 545.

Durante este período nasceram menos meninas do que meninos: em 1899 (47,9\%), 1910 (47,7\%), 1920 (47,5\%). Identificámos 12 crianças que foram enviadas para a Santa Casa da Misericórdia de Lisboa devido a problemas de saúde das mães. Observou-se que ocorreu um ligeiro decréscimo na média de dias da permanência das mães na enfermaria: em 1899, 20,4 dias, em 1910,

\footnotetext{
${ }^{16}$ Ibidem, p. 17.

${ }^{17}$ Ibidem, p. 42.

${ }^{18}$ Arquivo Nacional da Torre do Tombo, Hospital de S. José. Enfermaria de Santa Bárbara: Livros de registos, 1889, 1910, 1920.
} 
19,2 dias e em 1920, 18,1 dias. Globalmente a idade média das mães foi de 26 anos durante todo o período.

Quanto às profissões exercidas pelas mulheres, com maiores percentagens, em 1899, as criadas de servir eram maioritárias, 49,6\% das parturientes, as domésticas eram 23,5\% e as trabalhadoras domésticas 5,3\%; em 1910 as criadas diminuíram para $44,4 \%$ das mães, as domésticas subiram para 35,8\% e em 1920 as criadas reduzem-se para 30,5\% das parturientes e as domésticas aumentam para $48,6 \%$ das mães, sendo já a maioria das parturientes. ${ }^{19}$ As mulheres chegavam à maternidade, em primeiro lugar, vindas de suas casas e em menor percentagem de outra enfermaria. Em 1899, 43,6\% vinham de casa, $6,3 \%$ da casa dos patrões (as criadas) e 30,3\% da enfermaria de Santa Isabel; em 1910, 58,6\% das grávidas chegavam de casa e 33,1\% da enfermaria de Santa Emília; em 1920, 78,1\% provinha de casa e 20\% da enfermaria do Depósito. Neste último ano já 6,3\% das parturientes tinha recorrido a parteira ou a médico, em casa. Quanto à mortalidade das mães os dados revelam que foi muito reduzida: 1,9\%, em 1899, 1,8\%, em 1910 e 1920. Sobre a mortalidade dos bebés à nascença identificámos que a das meninas foi quase sempre menor: em 1899, 41,8\% do total dos falecimentos, 41,6\% em 1920.

A médica Adelaide Cabette relatou as difíceis condições das parturientes que eram internadas na maternidade. Frequentemente, as grávidas chegavam a Santa Bárbara e, não podendo ser admitidas, eram enviadas para enfermarias, como Santa Isabel e Santa Emília, esperando por uma vaga, ficando em contacto com doenças e contágios infeciosos, nomeadamente a tuberculose. No final do século XIX, aconteceu a parturiente já se encontrar em trabalho de parto e não existindo cama vaga, fazia-se uma cama no chão, com as nefastas consequências para a vida das mães e dos bebés. ${ }^{20}$ Em 1936, Costa Sacadura elucida que a enfermaria do Hospital de S. José designada por “Depósito" era a sala onde ficavam as camas para as grávidas com diversos problemas de saúde, infeções ou de abortos.

\footnotetext{
${ }^{19}$ Designavam-se por domésticas ou donas-de-casa as mulheres que cuidavam da casa e da família, não exercendo uma profissão no mercado de trabalho. As criadas de servir, ou serviçais, em regra exerciam a sua atividade remunerada em casas de famílias, onde também residiam. As mulheres inscritas como trabalhadoras domésticas podiam exercer diversas profissões ligadas à domesticidade: trabalhos de limpezas em residências privadas ou instituições, amas, cozinheiras, lavadeiras e porteiras.

${ }^{20}$ CABETTE, Adelaide de Jesus Damas Brazão e. A Proteção às Mulheres Grávidas Pobres como Meio de Promover o Desenvolvimento Físico de Novas Gerações. Lisboa, Tipografia Matos Moreira \& Pinheiro, p. 83.
} 


\section{A Maternidade Dr. Alfredo da Costa - a maternidade pública tão ansiada para a capital (1932-1943)}

Desde o final de oitocentos que os médicos, com destaque para o Professor Alfredo da Costa, defendiam a premência de uma maternidade pública, em Lisboa, com todos os serviços a funcionarem em boas condições.

Como observámos, o médico regente da cadeira de obstetrícia, doenças das puérperas e dos recém-nascidos, na Escola Médico-Cirúrgica de Lisboa, em 1899, insistia na necessidade da criação de mais maternidades, em Lisboa, para além da de Santa Bárbara. Em 1904, por proposta do médico obstetra Professor Manuel António Moreira Júnior (1866-1953), então ministro da Marinha e do Ultramar, o governo dirigido por José Luciano de Castro (1834-1914) inscreveu a verba de 19515 \$433 réis, no orçamento de Estado, para obras, a fim de adaptar a maternidade o antigo edifício da Escola Médico-Cirúrgica de Lisboa, situada no Hospital de S. José, o que não aconteceu. ${ }^{21}$ Já na República, o governo decidiu aproveitar uma área pertencente a uma extinta associação religiosa, a que se destinara a construção de um templo ao culto da Imaculada Conceição, no final da monarquia. Em 1 de Agosto de 1914, por portaria do presidente do governo de Bernardino Machado (1851-1944), foi nomeada a comissão constituída pelos professores Augusto Monjardino, Costa Sacadura e o arquiteto Miguel Ventura (devido ao seu falecimento, em 1919, foi substituído por Silvestre da Mota) com o objetivo de projetarem e construírem a maternidade. A construção iniciou-se (como ainda hoje está recordado na fachada principal) mas as sucessivas dificuldades económicas (entrada de Portugal na I Guerra Mundial, em 1916, e a crise financeira) levaram a que as obras se arrastassem no tempo. O Governo da ditadura militar, com António de Oliveira Salazar (1889-1970), como ministro das finanças, disponibilizou 1400 contos para a conclusão da maternidade, que foi inaugurada a 5 de Dezembro de 1932, com 250 camas. Coube, assim, ao novo regime o prestígio pela obra tão desejada e bem apetrechada de mobiliário e máquinas. 0 médico Alfredo de Magalhães, que fora médico da Escola-Cirúrgica do Porto e promoveu a fundação da maternidade de Júlio Dinis, do Porto, esclareceu as condições da Maternidade Dr. Alfredo da Costa devido às indemnizações a Portugal, após a I Guerra Mundial (cerca de 800000 marcos ouro) e comparou-as com a modesta situação com que se iniciou a fundação da maternidade Júlio Dinis, no Porto:

\footnotetext{
${ }^{21}$ «Maternidade» In Grande Enciclopédia Portuguesa e Brasileira... vol. XXVI, pp. 578-580; SACADURA, S.C. Costa. Subsídios para a História das Maternidades de Lisboa. Enfermaria de Partos de Santa Bárbara, Lisboa, s/1, 1939, p. 38; "Discurso na inauguração da Maternidade Dr. Alfredo da Costa, pelo Prof. Augusto Monjardino" In Arquivo de Obstetrícia e Ginecologia, Dezembro de 1933, Vol. I, ‥ำ
} 
“...obrigados a empregar materiais portugueses, não nos era dada a fortuna que teve a Maternidade Alfredo da Costa que se apetrechou de outillage de primeira qualidade, por conta das reparações alemãs". ${ }^{22}$

Foi diretor da Maternidade Dr. Alfredo da Costa o médico e professor catedrático da Faculdade de Medicina de Lisboa, Augusto de Almeida Monjardino, desde o início do seu funcionamento até 1941, por ter atingido o limite de idade.

Em 30 de Maio de 1932 tinha sido aprovado o Regulamento dos serviços de admissão de doentes, de higiene, farmacêuticos, clínicos, laboratoriais e de enfermagem da maternidade..$^{23}$

Na maternidade funcionavam as consultas normais e de urgência dos dois serviços clínicos de obstetrícia e de ginecologia. As doentes admitidas pertenciam a três categorias: pensionistas (as doentes que pagassem a sua hospitalização ou tratamento), as porcionistas (as mulheres que se apresentavam através de entidade municipal ou administrativa, ou que só pudessem pagar parte da quantia relativa ao internamento) e as indigentes (as mulheres que comprovadamente não possuíam recursos). Estas últimas, se residissem em Lisboa deveriam apresentar atestado de pobreza e se morassem fora da cidade tinham de apresentar um documento do município que se responsabilizava pelo pagamento dos serviços. As parturientes inscritas numa associação de socorros mútuos teriam os cuidados médicos pagos no total, ou parcialmente, pela associação mutualista. Com as mães doentes (só a partir do 8. mês de gravidez) eram admitidas crianças de leite, mas se o médico o considerasse prejudicial, para a criança, esta seria enviada para a Misericórdia de Lisboa, onde permaneceria durante a hospitalização da mãe. Eram definidos os preços a pagar pelas pensionistas, em quartos particulares ou nas enfermarias e por porcionistas, assim como o preço das operações e dos serviços clínicos.

Tendo acesso aos livros de registos de admissão das parturientes na Maternidade, identificámos quem eram as grávidas que acorriam a esta instituição pública da capital. Registar-se-iam muitas pensionistas, já que a maternidade estaria equipada com "tecnologia de ponta", segundo o médico do Porto, Alfredo de Magalhães? Decidimos analisar os livros de registos clínicos da Maternidade, escolhendo por amostragem alguns meses de 1932 (Dezembro, mês da sua abertura), 1933 e 1943 (último ano permitido para a

\footnotetext{
${ }^{22}$ MAGALHÃES, Alfredo de. Maternidade de Júlio Dinis: Notícia da sua fundação, separata de A Medicina Contemporânea, Lisboa, Centro Tipográfico Colonial, n. ${ }^{\circ}$ 11, 1939.

${ }^{23}$ Decreto n. 21 301, da Direcção Geral da Assistência, assinado pelo Ministro do Interior Mário Pais de Sousa.
} 
pesquisa, por motivos legais). ${ }^{24}$ Neste artigo, apenas compararemos os dados relativos a Dezembro de 1932 e a Dezembro de 1943. Durante este período nasceram mais meninos que meninas, $44,9 \%$ dos nascimentos em Dezembro de 1932 e 46,3\%, em Dezembro de 1943. Globalmente, a idade média das mães terá aumentado de 24 para 27 anos e manteve-se a média de internamento das mulheres em cerca de 16/17 dias. Relativamente às profissões das parturientes globalmente, nestes 12 anos, a maioria era doméstica, $86,2 \%$, seguidas de $5,7 \%$ de serviçais, $1,8 \%$ de operárias, $1,5 \%$ de costureiras, $1,0 \%$ de peixeiras, $0,9 \%$ de jornaleiras e vendedeiras. Em 1943, os pais eram maioritariamente empregados no comércio, 9,6\%, trabalhadores rurais, 7,3\%, trabalhadores, 6,5\%, empregados de escritório, 5,0\%, sapateiros e motoristas, 4,6\%, e operários, 3,8\%. Em Dezembro de 1932, predominantemente as parturientes eram solteiras, $54 \%$, e em Dezembro de 1943 , as casadas eram a maioria, $69,8 \%$ das parturientes (das 14 mulheres que exerciam profissões liberais, 86\% eram casadas). Contudo, muitas mulheres apesar de não terem o casamento legalizado constituíam famílias estáveis. Em 1943, 24,9 \% das parturientes viviam em "união de facto" pelo que os filhos juridicamente eram considerados ilegítimos, embora a maioria fosse reconhecido pelo pai e pela mãe. Pensamos que algumas referências que encontrámos a bebés reconhecidos só pelo pai se deve à morte da progenitora solteira. Em 1932, só 38,3\% dos filhos eram legítimos, em 1943, eram já a maioria, 67,3\%.

Das parturientes residentes na cidade de Lisboa, grande parte vivia na freguesia de S. Sebastião da Pedreira, 11\%, onde se situava a maternidade e uma das que conheceu maior crescimento demográfico, nos anos 30 do século $\mathrm{XX}$, mas grandes percentagens de mulheres viviam nas freguesias populares, como Santa Isabel, 12\%, ou Penha de França, 10\%. De fora de Lisboa, as parturientes residuais eram provenientes de diversos concelhos do país (talvez devido à previsão de partos com complicações). A esmagadora maioria das grávidas apresentara atestados de pobreza, de indigência, verificando-se uma diminuição ao longo da década, 79,4\%, em 1933, e 59,0\%, em 1943 (não existindo esta indicação para 1932). Algumas Câmaras subsidiaram as grávidas porcionistas consideradas com maiores carências económicas, destacando-se em 1943, as Câmaras de Loures, assistindo 7 grávidas, Oeiras, 3 grávidas e Sintra, Almada e Bombarral, 2 grávidas cada.

\footnotetext{
${ }^{24}$ Biblioteca e Arquivo Clínico da Maternidade Dr. Alfredo da Costa: livros de admissão das parturientes de 6 a 31 de Dezembro de 1932, 1933, 1943. Na nossa investigação escolhemos alguns meses por amostragem 1932 (Dezembro), 1933 (Novembro e de Dezembro) e 1943 (Dezembro). Porém, neste artigo apenas comparámos os dados de Dezembro de 1932, com os referentes a Dezembro de 1943.
} 


\section{A Beneficência privada da Maternidade Abraão Bensaúde (1927-1943)}

A documentação sobre a Maternidade Abraão Bensaúde, em Lisboa, é muito restrita, daí existirem algumas lacunas sobre o seu funcionamento, sendo inédita a maioria da informação que apresentamos. A maternidade teve a particularidade de possuir uma secção "secreta". Na Europa, as maternidades secretas foram fundadas para permitir a algumas grávidas, de meios económicos desfavorecidos e mais desprotegidos, maioritariamente mulheres sós, que sob anonimato, tivessem os seus filhos, com assistência médica, durante e após o parto.

O projeto da maternidade foi permitido pela benemérita Emília Bensaúde que, em testamento, deixou a quantia de 350 contos para a fundação e manutenção de uma maternidade para proteger raparigas abandonadas. 0 legado pretendia perpetuar, numa obra de beneficência pública na cidade de Lisboa, a memória de seu marido Abraão Bensaúde (1839-1912). ${ }^{25}$ Por morte de Emília Bensaúde, ficou testamenteiro o sobrinho Vasco Bensaúde, que assumiu a instalação e a manutenção da maternidade, como presidente, ficando diretor clínico o médico Costa Sacadura.

A Maternidade Abraão Bensaúde foi constituída como associação de beneficência, com estatutos aprovados por alvará de 26 de Julho de 1920, pelo Governador Civil de Lisboa, ficando obrigada a apresentar às autoridades administrativas de Lisboa os orçamentos por anos económicos.

Segundo os estatutos, a associação de beneficência propunha-se "recolher, auxiliar e tratar gratuitamente as mulheres pobres grávidas durante os últimos meses de gravidez e nos primeiros meses depois do parto" (art. 1.ํ). A associação começou por ser constituída por 15 sócios efetivos, que deveriam através da direção concretizar os fins da mesma e administrar os fundos com que se constituía e angariar novos. Ficou estipulado que as sessões da direção eram secretas, assim como as deliberações relativamente às pessoas socorridas pela associação (art.10. ${ }^{\text {) }}$. A maternidade iniciou funções em Maio de 1927 e foi solenemente inaugurada pelo presidente da República, António Fragoso Óscar Carmona (1869-1951), em 24 de Maio de 1928. Por pedido da direção da maternidade ao Ministério da Justiça e dos Cultos, foram admitidas três religiosas da ordem das Franciscanas Missionárias de Maria para os cuidados às grávidas, puérperas e recém-nascidos.

\footnotetext{
${ }^{25}$ O testamento de Emília Bensaúde foi efetuado em 18 de Fevereiro de 1919, em Terriet, sanatório Valmont, tendo Emília Bensaúde 70 anos e não tendo filhos. Vasco Elias Bensaúde era filho de Joaquim e Sofia Bensaúde.
} 
Num folheto de 1928 intitulado "Maternidade Abraham Bensaúde (Casa Maternal)", incluiu-se o "Regulamento da Secção das desprotegidas”. Indica-se que as mulheres admitidas na maternidade não eram obrigadas a dizer o seu estado civil. As mulheres que o pretendessem podiam ser inscritas sob um nome convencional, ou um número de ordem. Deveriam, no entanto, entregar ao médico um documento, contendo informações sobre o estado civil, e, se quisessem, as últimas vontades, que ficava num envelope fechado e lacrado. Só à saída da maternidade, o documento era entregue à mulher, ou aberto pelas autoridades, em caso de ocorrência grave. $O$ pessoal do estabelecimento era obrigado à maior discrição e só autoridades competentes e visitas autorizadas podiam entrar na maternidade.

Às mulheres competia-lhes executar várias tarefas: ajudar à limpeza da casa e fazer o enxoval do filho, pelo que recebiam uma remuneração, metade entregue diretamente à mãe e a outra parte só concedida quando a criança saísse da maternidade. ${ }^{26}$

A Comissão Central da Assistência de Lisboa, pelos registos de observação, entre 1927 e 1933, confirmou a visita à maternidade e "embora não precise do auxílio da Comissão Central, foi visitada pela Comissão que teve ocasião de admirar os benefícios que presta, a cargo da família Abraão Bensaúde”. ${ }^{27}$

Sobre as raparigas e mulheres acolhidas na Maternidade, apenas sabemos o que foi declarado pelo seu diretor clínico. Segundo a declaração de Costa Sacadura, em texto de 1954, a primeira grávida internada na maternidade tinha 13 anos e entrou a 3 de Dezembro de 1927, sendo posteriormente contratada como criada. Outras das internadas tinha vindo do norte do país, em situação extrema, pensara em suicídio. Ali teve o parto e o filho ficou na creche, que estava em organização, como instituição anexa. Mais tarde, a mulher casou e a criança ficou com os pais. Outra das raparigas abandonadas permaneceu na maternidade e concluiu um curso que lhe permitiu uma profissão remunerada e a educação da filha num colégio das Doroteias. Posteriormente, ambas partiram para uma das colónias (não sendo indicado o nome) onde terão constituído família.

Em Assembleia Geral da Associação reunida em 11 de Fevereiro de 1935, Vasco Bensaúde apresentou a proposta, que foi aprovada por unanimidade, devido à saída de Costa Sacadura da instituição:

\footnotetext{
${ }^{26}$ Governo Civil de Lisboa, Instituições de Assistência extintas. Cx. 76, processo 2004, ano 78, P.․ F/9-5.

${ }^{27}$ Arquivo Nacional da Torre do Tombo, Governo Civil de Lisboa, Registo de Cadastro às diferentes instituições de assistência privada de Lisboa, f. 129.
} 
"Considerando que o Sr. Costa Sacadura, durante os largos anos em que orientou os serviços da Maternidade e lhe dispensou os seus altos conhecimentos e competências, o fez com maior dedicação e interesse, procurando aperfeiçoar quanto possível o seu funcionamento, de forma a obter uma melhor eficiência dos benefícios que a Maternidade presta; Considerando que é da mais elementar justiça que na ata desta Assembleia fique consignado o apreço que à Associação merecem tais serviços proponho que se inscreva na ata um voto de louvor ao Sr. Sebastião Cabral da Costa Sacadura como homenagem e reconhecimento da Associação a sua Ex.cia".

Em 1954, numa Conferência, Costa Sacadura informou ter realizado uma estatística numa Maternidade que só recebia primigestas abandonadas, pobres (tudo indicando tratar-se da Bensaúde) em que a maior parte dos progenitores eram polícias e guardas republicanos (que segundo o médico, por isso, mais seriam agentes da imoralidade). ${ }^{28}$

Apenas sabemos que durante os anos 50 e 60 do século XX, acorreram à Maternidade Abraão Bensaúde mães solteiras e outras perseguidas pelo regime ditatorial de Salazar (que não podiam ter os filhos nos hospitais públicos), pois, na admissão, não lhes eram pedidos documentos de identificação. ${ }^{29}$

\section{A Maternidade da Companhia Portuguesa de Tabacos - a iniciativa privada do patronato (1927-1938)}

Desde finais dos anos 20 que algumas Companhias prestavam serviços materno-infantis às trabalhadoras. A Companhia Portuguesa de Tabacos, em Lisboa, em 1927, criou uma Maternidade com consultas de grávidas, puérperas e de pediatria. Foi diretor clínico, o médico Manuel Vicente Moreira (1866-1953).

A fundação das maternidades fabris enquadrava-se nas medidas médicas e higienistas da época, em meio industrial. Pela legislação, estipulava-se que competia ao médico da fábrica e dos estabelecimentos industriais: "aconselhar aos industriais a adopção de medidas de higiene". ${ }^{30}$ No âmbito da assistência à mãe, especificava-se as competências do médico do estabelecimento ou serviço: "Exercer vigilância sobre as grávidas, indicando a moderação do trabalho ou suspensão"; "Vigiar o estado de saúde das mães durante o período

\footnotetext{
${ }^{28}$ SACADURA, S. C. da Costa. Assistência Materno-Infantil. Males, remédios e males que ainda não foram remediados. separata do Jornal Médico, 1954, Vol. XXIV, p.15. Apesar dos contactos institucionais não conseguimos localizar o livro escrito por Costa Sacadura sobre a Maternidade Abraão Bensaúde.

${ }^{29}$ Ver partos clandestinos: http://www.instituto-camoes.pt/bases/25abril/partosclands.htm, acedido em 26/11/2009. A Associação de Beneficência Abrão Bensaúde foi declarada extinta em 1977.

${ }^{30}$ Diário do Governo n. 240, I Série, 29 de Outubro de 1927, Sábado, artigo 19.ํ, \$3.
} 
de amamentação"; "Mandar moderar ou suspender o trabalho das mulheres .... ou mudá-las de ocupação". ${ }^{31}$

Como vimos, a situação do trabalho das mulheres, principalmente casadas e mães, sempre foi muito controversa. Nos anos 30, do século XX, o médico Manuel Vicente Moreira (1898-1975) considerou que além das consultas deveria caber ao médico a decisão de abolir o trabalho fabril da mulher durante o período da gestação e da amamentação. Na sua perspetiva, não bastava a permissão legislativa para as mães trabalhadoras amamentarem os filhos, meia hora de manhã e à tarde, as mães deveriam cuidar dos filhos durante todo o dia. 0 médico defendia o aumento dos salários dos homens casados, para que se concretizasse o denominado "salário familiar", situação que se enquadrava na ideologia que se espalhava pela Europa sobre a função da mulher cuidadora da família, entre as duas Guerras Mundiais.

A Maternidade destinava-se a cinco serviços clínicos: o dispensário com a consulta pré-natal, inaugurado em 1927, o lactário a funcionar em 1928, o serviço de partos a partir de 1931, a assistência domiciliária pelo médico e visitadora e a fiscalização médica durante o trabalho fabril das grávidas e das mulheres que amamentavam.

Além da ação médica, a maternidade procurava ter uma função social, analisando as situações económicas das famílias dos seus trabalhadores/as, visitando as habitações e oficinas fabris e, no caso de encontrar nestas últimas inconvenientes para a grávida ou o lactante, propunha mudanças para melhorar a situação das operárias no trabalho.

As parturientes eram as operárias da Companhia Portuguesa de Tabacos e as mulheres dos operários. As operárias tinham direito a internamento gratuito durante dois meses, um antes do parto e um mês após o mesmo, com subsídios iguais aos atribuídos aos operários/as doentes, 5 \$33 diários. Pelas informações recolhidas pelo médico para o ano de 1938, numa amostragem de 25 operárias da Companhia, observa-se que as tabaqueiras residiam em bairros, vilas e becos próximos da Maternidade e da fábrica tabacos de Xabregas. Destas operárias, 12 estavam grávidas e 16 mulheres tinham 3 ou mais filhos, o que mostra a extensão de muitos destes agregados familiares. ${ }^{32}$

\footnotetext{
${ }^{31}$ Diário do Governo n. 245, I série, 5 de Novembro de 1927, Sábado, artigo 8.․, §3, §4.ํe §5.․․

${ }^{32}$ No estudo realizado entre 1933 a 1935 a 405 famílias operárias da Companhia Portuguesa de Tabacos, Manuel Vicente Moreira observou que a maioria das famílias, 73, 3\%,era constituída por 5 pessoas, assim distribuídas; $23,3 \%$ por 3 pessoas, $18,7 \%$ por 5 pessoas, $17,2 \%$ por 4 pessoas $414,0 \%$ por 2 pessoas. Mais de $1 / 4$ dos agregados familiares tinham mais de 6 elementos (de 6 a 16 pessoas). Ver: MOREIRA, Manuel Vicente. Ensaios Médico-Sociais II: Habitações operárias, Separata de O Instituto, Coimbra, Gráfica de Coimbra, 1941, p. 24.
} 
Só progressivamente as grávidas perceberam, por exemplo, a importância das análises e da medição da tensão arterial como prevenção da eclampsia. Pela documentação, verificámos que, entre 1927 e 1936, o número total de consultas triplicou, o mesmo acontecendo com as mulheres consultadas que passaram de 96, em 1927, para 275, em 1936, assim como as crianças que aumentaram de 77 para 244 , no mesmo período. A taxa da mortalidade infantil dos bebés observados na maternidade, até completarem 1 ano, foi em 1928, de $11,2 \%$, diminuindo para 6,06\%, em 1934, enquanto em Lisboa, no mesmo período, a taxa global da mortalidade pouco reduziu, de $20 \%$ para $18 \%$. Além das consultas médicas prestaram-se diversos tratamentos: antissifilíticos, sessões de raios ultravioletas, vacinação contra a varíola e BCG, foram realizados 376 partos e abortos (não discriminados) e 25 operações obstétricas. ${ }^{33}$

$\mathrm{Na}$ maternidade também se distribuía leite e farinhas, em regra, entregues no período das pesagens de 15 em 15 dias, e doavam-se enxovais a recém-nascidos. Contudo, as mulheres dos operários só podiam levar os lacticínios depois de provarem que trabalhavam fora de casa, local para onde não podiam levar o filho, e só depois do primeiro mês de puerpério, porque por lei deveriam interromper o trabalho por quatro semanas a seguir ao parto.

A maternidade distribuiu folhetos informativos para esclarecimento das mães, com prescrições gerais relativas à gravidez, à saúde e alimentação das crianças. Aconselhava-se às mães os horários das mamadas em articulação com o horário fabril, prevendo-se, conforme a lei, 2 mamadas na fábrica, uma de manhã (9.00h) e outra à tarde (15.00h). Também foi dinamizada uma biblioteca com obras de autores/as ainda hoje reconhecidos/as, nomeadamente: Conselhos às Mães, da médica Branca Rumina (1898-1988), médica dos lactários da Câmara Municipal de Lisboa, das Creches da Misericórdia de Lisboa e diretora do Posto de Puericultura n. .4 da Junta Geral do Distrito de Lisboa, Cuidai das Crianças pela alimentação e pela higiene, de Sara Benoliel (1898-1970), jornalista e feminista, Cartilhas Maternais, do pedagogo João de Deus (1830-1896).

Na instituição realizaram-se estágios para assistentes sociais e enfermeiras. Em 14 de Dezembro de 1938 a direção da OMEN (Organização das Mulheres pela Educação Nacional), da MPF de Beja (Mocidade Portuguesa Feminina), ambas as organizações criadas em 1936, e o Sindicato das Enfermeiras realizaram uma visita à Maternidade, elogiada por Manuel Vicente Moreira. 0 diretor

\footnotetext{
${ }^{33}$ MOREIRA, Manuel Vicente. Apontamentos sobre Algumas Realizações de Proteção à Mãe Pobre, Lisboa, Tipografia da Companhia Portuguesa de Tabacos, 1939, p. 2 e MOREIRA, Manuel Vicente. Maternidade da Companhia Portuguesa de Tabacos: Bases da Organização e Síntese do Movimento (1927-1933. Lisboa, Tipografia da Companhia Portuguesa de Tabacos, 1934, pp. 5-6.
} 
pareceu querer demonstrar a coadunação dos princípios da Maternidade com os defendidos por estas organizações fundadas pelo Estado Novo, com vista a orientarem as mães na divulgação das noções de higiene e de puericultura. No mesmo espírito que pretendia educativo, o médico realizou o filme "A ação médico-social da Companhia Portuguesa de Tabacos" rodado nas oficinas, nas casas das operárias e na maternidade, apresentado em 1931 no Congresso Internacional de Protecção à Infância, realizado em Lisboa, considerado o primeiro filme português de puericultura e higiene industrial.

\section{A Maternidade da Associação de Socorros Mútuos de Empregados no Comércio de Lisboa (1941-1942) - a interajuda entre trabalhadores/as}

A Associação de Socorros Mútuos de Empregados no Comércio de Lisboa, com sede em Lisboa, foi fundada em 16 de Junho de 1872 e aprovada por alvará em 29 de Agosto do mesmo ano. Em 1913 a associação estabeleceu-se no atual edifício - o antigo palácio dos Condes de Aveiras, Marqueses de Vagos, na freguesia de S. Cristóvão e S. Lourenço.

Era no final do século XIX uma associação masculina e assim se manteve até 1930 . Os sócios tinham de viver na cidade de Lisboa e exercer uma profissão ligada ao comércio (caixeiros, despachantes de alfândega, farmacêuticos, alfaiates com estabelecimentos). Através do pagamento de joias e quotas, os associados tinham direito a socorros na doença, por incapacidade, desemprego ou prisão e a consultas de especialidade domiciliárias. ${ }^{34}$

Relativamente à entrada das sócias, pelo menos, na Assembleia Geral de 26 de Agosto de 1920 foi deliberado "aprovar em princípio, a admissão de sócios do sexo feminino". ${ }^{35}$ Contudo, só em Abril de 1930 foi admitida uma médica no corpo clínico, a Dr. ${ }^{a}$ Raquel Cabeçadas, com o objetivo de proceder à inspeção das candidatas a sócias, começando em Outubro a assistência às beneficiárias, inaugurando-se, para o efeito, o dispensário, internato e os serviços de Clínica Geral e Cirurgia. Em 1931, a associação contava 9691 sócios e 248 sócias.

As parturientes começaram por ser atendidas em casa por três parteiras diplomadas. Em 29 de Junho de 1941, dia de aniversário da associação, foi inaugurada a maternidade, que contou com a presença do Presidente da República, Óscar Carmona e o subsecretário das Corporações e Previdência

\footnotetext{
${ }^{34}$ Alvará de 20 de Julho de 1893, Diário do Governo n.ํ278, I Série, de 7 de Dezembro de 1893.

${ }^{35}$ COELHO, Elmano de Lage Simões. Cem Anos Depois (1872-1972), Lisboa, Publicação Comemorativa do Centenário da Associação de Socorros Mútuos de Empregados no Comércio de Lisboa, 1972, p. 43.
} 
Social, Joaquim Trigo de Negreiros (1900-1973). Pelas fontes acedidas, apenas conseguimos identificar, de 10 de Julho a 31 de Dezembro de 1941, o nascimento de 10 bebés na Maternidade. Em 1942, a associação admitiu 2 enfermeiras-parteiras e iniciou a consulta de pediatria e puericultura, altura em que a enfermaria foi remodelada para funcionarem 3 quartos particulares. No ano seguinte, a 19 de Dezembro, ocorreu a primeira festa em prol das crianças nascidas na Maternidade, assistindo as que frequentavam as consultas de pediatria e puericultura. Foram entregues enxovais a crianças pobres, das freguesias de S. Cristóvão e S. Lourenço, confecionados por mulheres de dirigentes associativos. $\mathrm{Na}$ impossibilidade de consultarmos as fichas clínicas, foi-nos possível contactar com as mutualistas nascidas entre 1918 e 1941. Retivemos, pelas nossas conversas, que muitas associadas foram inscritas pelos pais, ainda jovens, algumas tiveram os filhos na maternidade da associação, na década de 60 , e quase todas proferiram que o mutualismo era um ideal.

\section{A Maternidade do Porto fundada pelo médico Artur Maia Mendes - uma associação de beneficência particular (1910-1920)}

Mais a norte do país, a Maternidade do Porto foi fundada em 1910, por Artur Salustino Maia Mendes (1857-1920), médico no Hospital de Santo António, no Porto, e chefe de clínica médica, cirúrgica e obstétrica da Escola Médico-Cirúrgica do Porto, entre 1903 e 1910. A maternidade adotou a divisa: «Proteção às Mães e aos recém-nascidos», ficando diretor Artur Mendes até à sua morte em 1920. Até 1924, a maternidade foi dirigida pelo filho, o cirurgião Arnaldo Maia Mendes, que faleceria nesse ano, entrando a maternidade em declínio.

Segundo os estatutos aprovados pelo Governador Civil, estipulava-se que a Maternidade do Porto era uma associação de beneficência, com número ilimitado de sócios e de duração indefinida. ${ }^{36}$ Todas as pessoas, de ambos os sexos, podiam fazer parte da associação desde que tivessem rendimentos (próprios ou da profissão). Como estava legislado para todo o movimento associativo, as mulheres casadas, para serem sócias, necessitavam da autorização dos maridos e só os/as associados/as maiores de idade podiam fazer parte das assembleias gerais, eleger para os cargos diretivos e serem eleitos.

Previam-se diversos cuidados médico-assistenciais gratuitos, consultas para as grávidas, tratamento gratuito hospitalar no parto e no período de

\footnotetext{
${ }^{36}$ Estatuto da Maternidade do Porto, Associação de Beneficência, s/ed., capítulo II- Admissão de sócios, p. 8 e capítulo III- Direitos e Deveres dos sócios, p. 9. Os Estatutos foram aprovados a 3 de Agosto de 1910, pelo Governador Civil Dr. José Diogo Arroio, por Alvará de 12 de Agosto de 1910.
} 
puerpério e das crianças, desde que se comprovassem a indigência; o estabelecimento de salas especiais e parques de passeio para descanso das mulheres nos últimos meses de gravidez e no primeiro após o parto e o fornecimento de medicamentos, alimentos e leite às crianças que não pudessem ser amamentadas pelas mães (artigo 2. ${ }^{\circ}$ ). Os fundos da Associação eram provenientes de donativos, legados, quotas dos sócios e das receitas das pensionistas na maternidade. Juntaram-se no apoio à associação, 36 farmacêuticos, que forneceram medicamentos gratuitos e o médico da maternidade, Dr. Mário de Castro, oferecendo vacinas do Instituto de vacinação do Porto, que dirigia.

Em regra, as mulheres que procuravam a maternidade constituíam três grupos: as grávidas com problemas decorrentes do seu estado: anemias, intolerância gástrica, enjoos, vómitos e eclampsia, as grávidas com diversas doenças - obesidade, tuberculose, sífilis, tumores no abdómen e do útero, cancro - e as mulheres que nos quatro ou cinco primeiros meses do ano procuravam um diagnóstico do seu estado, voltando posteriormente à maternidade para aí terem os seus partos.

Nas crianças salientavam-se mais as doenças do aparelho digestivo devido "à má nutrição que têm em geral as mães na maneira de alimentar os seus filhos... os que pagam maior tributo são os que são alimentados artificialmente". ${ }^{37}$ Juntava-se a esta causa o desregulamento do horário das refeições, com excesso alimentar, a má qualidade do leite, que se deteriorava no Verão e o desmame prematuro. No relatório apresentado pelo Dr. Angello Pereira, clínico da consulta das crianças, criticou as mães que levavam os filhos tardiamente às maternidades: "Se algumas se podem apresentar como verdadeiros modelos de sacrifício e amor maternal, outras há que são o protótipo do desleixo e da miséria, a que não é estranha a sua dose de estupidez".

Não deixa de ser curioso que esta situação era reconhecida em 1905 pela jornalista, escritora e feminista, Ana de Castro Osório, em 1905: “A indiferença com que a mulher vê ir para o céu o filho da sua incúria, quasi sempre, mata, é bem conhecida dos médicos para precisar ser mais frisada" ${ }^{38} \mathrm{~A}$ pobreza das famílias, em regra numerosas, e o excesso de trabalho das mulheres dentro e fora de casa, não foram fatores indicados nos relatórios médicos.

\footnotetext{
${ }^{37}$ MENDES, Artur Maia. Maternidade do Porto: Relatório da Montagem do Estabelecimento e de Dezoito Meses de Exercício, desde 1 d'Outubro de 1910 até 31 de Março de 1912. Porto, Papelaria e Tipografia Azevedo de Azevedo \& Filho, 1912. Relatório do Dr. Angello Pereira, p. 34.

${ }^{38}$ OSÓRIO, Ana de Castro, Às Mulheres Portuguesas, Lisboa, Livraria Editora Viúva Tavares Cardoso, 1905, p. 171.
} 
O Dr. Júlio Abelard Teixeira, clínico também responsável por consultas de crianças, destacou três grandes vertentes nas suas consultas de pediatria: médico, higienista e puericultor. A sua prioridade era limitar a terapêutica medicamentosa e educar as mães nos preceitos higiénicos e de aleitamento.

Pelo relatório do Dr. Mário de Castro, que incluiu com uma listagem de 292 crianças vacinadas entre 18 de Dezembro de 1910 e 31 de Março de 1912, podemos inferir as suas idade e residências, tanto da cidade do Porto, como de fora do concelho. ${ }^{39}$ As crianças estavam equiparadas por sexo, em maior percentagem as que tinham mais de 12 meses (56,21\%). Apesar do resultado das vacinas ser maioritariamente positivo (88\%), não compareciam para verificação dos resultados $4 \%$ das crianças (talvez devido à longa distância entre a residência e a maternidade, já que 12 crianças viviam fora da cidade, ao horário de trabalho das mães, que impossibilitava as deslocações, ou por integrarem os dados da mortalidade infantil). Comparando as áreas de residência das crianças e o regulamento da maternidade verifica-se que viviam nas freguesias mais carenciadas da cidade do Porto: Cedofeita, Santo Ildefonso, Miragaia e Paranhos.

Desde a inauguração da maternidade, em 1 de Outubro de 1910, até 31 de Dezembro de 1919 realizaram-se 86284 tratamentos gratuitos a mulheres e a crianças, indigentes, além dos internamentos, a cujos números não conseguimos aceder.

\section{A Maternidade Dr. Daniel de Mato em Coimbra (1911-1938) - uma criação republicana}

Em Coimbra, cidade onde em 1290, foi fundada a mais antiga universidade do país, em 1905, Daniel Ferreira de Matos Júnior (1850-1921), médico, cirurgião, parteiro e professor da Faculdade de Medicina da Universidade de Coimbra, regente das cadeiras de Clínica cirúrgica e ginecologia, reitor da Universidade de Coimbra, deplorava a não existência de maternidades em Portugal. No ano seguinte, estudantes finalistas de medicina, da Universidade de Coimbra, iniciaram, a nível nacional, uma angariação de fundos para a criação de uma maternidade em Coimbra.

Só na República, o decreto de 22 de Fevereiro de 1911, assinado pelo Ministro do Interior, António José de Almeida (1866-1929), criou uma maternidade em Coimbra, anexa à Faculdade de Medicina da Universidade de Coimbra. Pelo decreto e o regulamento da maternidade observa-se que se dirigia às

${ }^{39}$ MENDES, Artur Maia. Maternidade do Porto ...., Relatório do Dr. Mário de Castro, p. 37. 
mulheres grávidas, do distrito de Coimbra, que aí procurassem a assistência que necessitavam e à proteção da saúde das crianças pobres, criando-se consultas regulares para as mães e as crianças.

A Comissão administrativa da maternidade, eleita trienalmente, era constituída pelo administrador dos Hospitais da Universidade de Coimbra, dois membros efetivos (vogais) e o diretor da maternidade, professor da Faculdade de Medicina.

A clínica obstétrica dos Hospitais da Universidade de Coimbra, foi denominada de clínica Dr. Daniel de Matos e, a partir de 1917, maternidade Dr. Daniel de Matos, ficando diretor o médico Álvaro de Almeida Matos (18801954) e, após essa data, o médico Álvaro Fernando de Novais e Sousa (18861962) até 1956, quando perfez 70 anos.

Pelos livros de registos da aceitação das mulheres pela administração dos Hospitais da Universidade de Coimbra, de 1903 a 1943, observámos por estimativa que as parturientes tinham diversas profissões: criadas de servir, jornaleiras, domésticas, costureiras, serventes, sendo em 1943, a maioria das parturientes casadas, tal como observámos para as maternidades de Lisboa, o que mostra que o casamento legal tendia a generalizar-se.

A maternidade era constituída por duas secções: a de serviços de partos, de clínica e lactário e a do hospício, que ficava encarregada da criação de crianças assim denominadas: dos expostos (crianças até aos 7 anos, entregues aos cuidados da instituição), dos desvalidos (filhos de famílias muito pobres) e dos abandonados (crianças encontradas, ignorando-se a identidade dos pais).

Em Dezembro de 1912 iniciaram-se as consultas externas para grávidas. Segundo o regulamento da maternidade destinavam-se às mães mais desprotegidas e permitiam o acesso a consultas domiciliárias (às grávidas que vivessem fora da área fiscal de Coimbra), ao internato e à assistência pelo lactário e subsídios de lactação, no primeiro ano de vida. As grávidas podiam permanecer na maternidade durante 20 dias após o parto, sendo garantido o descanso nas últimas semanas de gravidez.

Esta assistência, na maternidade e no domicílio, era concedida após comprovativo de atestado de pobreza. Atribuía-se, também, subsídio de «parturição», no valor de $2 \$ 000$, às puérperas em “condições de miséria extrema”, às que não pudessem ser internadas, às mulheres casadas abandonadas, viúvas ou solteiras, vivendo do seu salário, após provarem ter-se mantido na cama 8 dias após o parto. Para estas mulheres também estava previsto o subsídio de "puerperalidade" de montante igual a um ou dois meses do subsídio de lactação, possibilitando o descanso às que trabalhavam fora de casa, desde que 
comprovassem não ter executado nenhum trabalho penoso ou que exigisse esforço considerável, durante 40 dias a seguir ao parto. 0 médico Novais e Sousa concluiu que esta legislação não melhorou a vida das mulheres, devido à insignificância das verbas e às condições exigidas para o seu acesso, os atestados passados pelo presidente da junta de paróquia ou do regedor, com a prévia informação de pessoa idónea, certificando as condições exigidas. Os subsídios de lactação a crianças com menos de um ano, nascidas no distrito de Coimbra, eram fornecidos quando os progenitores ou familiares próximos provassem a sua pobreza e bom comportamento. A importância do subsídio variava entre um valor mínimo de $\$ 800$ réis e um máximo de $2 \$ 500$ réis, concedido apenas às mães que não pudessem amamentar, ou a criança que fosse órfã de mãe. Em ambos os casos, previa-se a contratação de uma ama para amamentação da criança. Pelo orçamento da maternidade para o ano de 1914-1915, o maior montante estava previsto para o subsídio de lactação no valor de $3612 \$ 20$ e apenas de $200 \$ 00$ para cada um dos subsídios de "puerperalidade" e de "parturição".

Em 1938, António Alberto Dias e Costa (1902-1988), assistente de obstetrícia da Faculdade de Medicina da Universidade de Coimbra e médico na maternidade Dr. Daniel de Matos, apresentou provas de finalista do 5. ano. Na sua dissertação registou alguns casos clínicos vivenciados e demonstrou que a melhoria das comunicações e transportes tinham trazido anualmente mais mulheres à maternidade, aumentando as admissões: em 1930, 465, em 1935, 644 e em 1936, 754.

Relatou uma situação ocorrida a 18 de Novembro de 1935, reflexo das duras condições das parturientes das zonas de fora das cidades quando procuravam ser assistidas em meio hospitalar. Uma mulher doméstica, casada, de 40 anos, deu entrada na maternidade, no final da gravidez. Terá vindo da sua aldeia (Ceira), a pé, percorreu $8 \mathrm{~km}$ para ser assistida na maternidade. Sentiu dores fracas no ventre, perdeu algum líquido pela vagina e expulsou um embrião achatado que levou até à maternidade. 0 médico explicou que se tratou de um "f. papyraceus compressus" ao qual vinha ligado $20 \mathrm{~cm}$ de cordão, que não foi necessário laquear pois terá saído espontaneamente. ${ }^{40}$

Alberto Costa, no período entre 1932 e 1938, perante a procura da maternidade por jovens menores de 21 anos para aí terem os seus filhos, ou devido a complicações da gravidez, quase todas analfabetas, de origem rural

${ }^{40}$ COSTA, Alberto Costa, Clínica Obstétrica da Faculdade de Medicina de Coimbra, Serviço do Prof. Novais e Sousa. Alguns casos clínicos comentados e documentados (Curriculum Vitae - II parte), Coimbra, Clínica Obstétrica da Faculdade de Medicina de Coimbra, 1938, p. 23. 
e muito humilde, abandonadas pelas famílias ou pelos progenitores dos filhos, (algumas registadas como meretrizes na polícia), estabeleceu uma cooperação com o juiz da Tutoria Central de Coimbra, para o envio das menores para reformatórios, tutoria ou colónia penal, consoante as situações vividas (abandono, prostituição, abortos) até serem consideradas recuperadas "com bom comportamento". ${ }^{41}$

\section{Conclusão}

Neste artigo analisámos os partos e os seus contextos sociais e familiares, em maternidades, em Portugal, entre 1889 e 1943, tomando em consideração algumas maternidades regionais, fundadas nas cidades de Lisboa, Porto e Coimbra.

Desde a monarquia ao Estado Novo, relacionou-se o trabalho das mulheres das classes populares (com maiores taxas na cidade do Porto, circundada por áreas rurais) com a mortalidade infantil e a queda da natalidade. Estas questões foram sistematicamente abordadas pelo poder político, médicos e dirigentes associativos, mas a condicionar a ação médica estavam as dificuldades económicas do país, decorrentes das crises económicas internas e das consequências das Guerras Mundiais. De destacar que os médicos sempre estiveram bem informados sobre as novidades, que a nível obstétrico e de acompanhamento pós-natal, aconteciam a nível internacional, devido à circulação de revistas da especialidade e às deslocações a congressos fora do país.

Observámos que a visão política e social dominante remetia preferencialmente os partos para casa, por motivos morais e afetivos. Progressivamente, comprova-se uma lenta evolução nos serviços de cuidados materno-infantis nas maternidades em estudo, verificável para os anos 30 e 40 do século XX, pela melhoria das condições de funcionamento da maternidade Santa Bárbara e da maternidade Dr. Alfredo da Costa, edificada de raiz, com o melhor equipamento e mobiliário da época. Também a facilidade dos meios de comunicação, como na zona de Coimbra, terá possibilitado o acesso de mais mulheres à maternidade Dr. Daniel de Matos, nos anos 30.

Identificámos que até 1943, nas maternidades de assistência pública (Santa Bárbara e Dr. Alfredo da Costa, em Lisboa e Dr. Daniel de Matos, em Coimbra) e nas que eram associações de beneficência privada, ou a cargo de

\footnotetext{
${ }^{41}$ COSTA, Alberto. A acção social nas Maternidades e Outras Clínicas Hospitalares, quanto ao Combate e Profilaxia da Prostituição de Menores, separata da Acção Médica. Lisboa, Imprensa Lucas \& C. a Fasc. XXI, 1941. O médico relata as vivências de 8 jovens grávidas que entraram na Maternidade.
} 
beneméritos (maternidade do Porto e Abraão Bensaúde, em Lisboa) as parturientes acolhidas gratuitamente eram mulheres indigentes, que tinham de comprovar a sua condição de pobreza. Exerciam profissões como criadas de servir, costureiras, peixeiras, operárias, vendedeiras, domésticas, exercendo os pais das crianças profissões predominantemente manuais. Globalmente, entre as duas Guerras Mundiais, predominaram no acesso às Maternidades as mulheres domésticas, de certeza, devido à representação social que defendia a conceção da mulher no lar, cuidadora da família. À Maternidade Dr. Alfredo da Costa, apesar de também admitir pensionistas, só um reduzido número de mulheres das classes liberais ou do terciário a ela acorreu, talvez quando se temiam complicações nos partos. Assim, até à década de 40 do século XX, só as mulheres trabalhadoras mais pobres recorreram às maternidades públicas. A maternidade Bensaúde teve a particularidade de possuir a única secção "secreta" que identificámos para Portugal, em que as grávidas eram jovens e mulheres abandonadas, admitidas sem ser necessário identificarem-se.

Nas maternidades da Companhia Portuguesa de Tabacos e da Associação de Socorros Mútuos de Empregados no Comércio de Lisboa, estamos já na esfera da previdência social. Na maternidade da associação mutualista as mulheres pagavam joias e quotas, segundo o ideal mutualista de interajuda. Na maternidade a cargo do patronato, já com preocupações higienistas e de acompanhamento das trabalhadoras grávidas e puérperas, aplicava-se a legislação sobre o descanso obrigatório das mulheres após o parto e a criação de maternidades onde trabalhassem mais de 400 mulheres.

Em suma, estas maternidades regionais de Portugal, onde ocorreram os partos, integram-se nas instituições que forneciam cuidados de saúde materno-infantil, através dos sistemas de proteção da assistência social e da previdência, constituindo as origens do Estado-Providência em Portugal. Enquanto pela assistência social se socorriam as mulheres trabalhadores mais pobres, que também eram estigmatizadas, com a previdência social começavam a despontar os direitos sociais, devido aos descontos efetuados pelas trabalhadoras, por iniciativa patronal ou dos trabalhadores associados no mutualismo.

Artigo recebido para publicação em 11/08/2016

Artigo aprovado para publicação em 09/11/2016 